\title{
PSO based Hybrid PID-FLC Sugeno Control for Excitation System of Large Synchronous Motor
}

\author{
Hung Quoc Duong ${ }^{1}$, Quang Hong Nguyen ${ }^{1}{ }^{\oplus}$, Duy Tien Nguyen ${ }^{1}$, Lanh Van Nguyen ${ }^{1,2 *}{ }^{*}$ \\ ${ }^{1}$ Thai Nguyen University of Technology (TNUT), Thai Nguyen city, Thai Nguyen 251750, Vietnam. \\ ${ }^{2}$ University of Technology Sydney (UTS), 15 Broadway, Ultimo NSW 2007, Australia.
}

\begin{abstract}
This paper proposes a hybrid control system integrating a PID controller and a fuzzy logic controller, using the particle swarm optimization (PSO) algorithm to optimize contro parameters. The control object is an excitation system for a large synchronous motor, which is widely used in large power transmission systems. In practice, the change in load and excitation source can affect the operating mode of the motor. Therefore, a hybrid controller is designed to stabilize the power factor, resulting in better working performance. In the control algorithm, a PID controller is initially designed using PSO to optimize the control coefficients. The FLCSugeno control is then integrated with the PID, in which PSO is utilized to optimize membership functions. Numerical simulation results demonstrate the advantages of the proposed approach.
\end{abstract}

\section{Keywords:}

Synchronous Motor; Excitation System;

Particle Swarm Optimization;

PSO; Fuzzy Logic Controller.

\section{Article History:}

$\begin{array}{llll}\text { Received: } & 04 & \text { October } & 2021 \\ \text { Revised: } & 06 & \text { December } & 2021 \\ \text { Accepted: } & 23 & \text { December } & 2021 \\ \text { Available online: } & 27 & \text { February } & 2022\end{array}$

\section{1- Introduction}

Synchronous motors have apparent advantages in efficiency, torque, and operational stability. Therefore, it is widely utilized in large power transmission systems. The power factor correction of high-power synchronous motors is helpful in applications where the motor is subjected to high transient load variations. This power factor is measured and sent to the controller; a control signal is then calculated and sent to the thyristor static rectifier to adjust the value of the excitation source supplied to the rotor winding of the motor. Accordingly, the traction torque of the synchronous motor is adjusted during transient load [1,2]. In addition, the power controller recognizes the voltage drop of the power grid within a certain allowable period to provide a solution to adjust the field current accordingly [3, 4]. Another application of power factor correction is to control plant power factor variations caused by other loads such as asynchronous motors running under or without load, thereby improving the voltage quality of the plant [5, 6]. Therefore, stabilizing the value of the power factor will indirectly stabilize the operating mode of the motor.

PID is a controller proposed by Araki [7], and it has become a widely used tool in the industry. Determining the PID controller parameters can be done by different methods, of which Ziegler-Nichols [8] is a very effective method when the mathematical model is not required to be known [9-11]. The combined Ziegler-Nichols and trial and error methods have refined the accuracy of the controller parameters [12-15]. Pengpraderm et al. (2017) [15] designed a PI controller to excite the rotor of the synchronous motor to track the power factor set point. This method further refines the controller parameters and achieves better results than those obtained using only Ziegler-Nichols. In Al-Kababji \& Al-Sammak (2002) [16] study, the experience of operators is used to adjust the PID controller parameters. In the steady-state, the above studies show that the response still has relatively large fluctuations.

* CONTACT: vanlanh.nguyen@uts.edu.au

DOI: http://dx.doi.org/10.28991/ESJ-2022-06-02-01

(C) 2022 by the authors. Licensee ESJ, Italy. This is an open access article under the terms and conditions of the Creative Commons Attribution (CC-BY) license (https://creativecommons.org/licenses/by/4.0/). 
The design of the PID controller and the adjustment of the coefficients is simple, especially for linear objects. For nonlinear systems, however, the PID controller becomes inefficient. To solve this problem, a fuzzy tuning technique was introduced to tune PID controller parameters [17-20]. In these methods, however, the system structure is often quite complex. To reduce the complexity, an independent fuzzy logic controller (FLC) was applied to control the excitation [21, 22]. Although this approach obtains a relatively small steady-state error, the response time is prolonged due to the delayed nature of the fuzzy controller. The FLC controller has the advantage of responding well to the control requirements, especially for objects that do not need to know the mathematical model in advance. However, there is a difficulty when designing a fuzzy controller as many factors affect the controller's input/output relationship, such as the form of the membership function, the selection of the join, drag, and defuzzification operations. This choice does not have a specific rule but heavily depends on the expert knowledge of the designer. To solve this difficulty, optimization algorithms have been proposed, such as particle swarm optimization [23, 24]. Compared with mathematical algorithms and other heuristic optimization techniques, PSO is simple, easy to implement, robust to control parameters, and has high computational efficiency. In this study, PSO is proposed to optimize the parameters of the PID and FLC controllers in the hybrid control system to adjust the power factor in the excitation control system of the synchronous motor.

The main contributions of this work include (i) the critical analysis of the effect of load and excitation source on the operating mode of a synchronous motor, and (ii) the integration of PID and FLC schemes using the PSO algorithm to achieve a stable power factor. The rest of this paper is structured as follows. The problem description is given in Section 2. Section 3 describes the control design, and Section 4 presents simulation results. Finally, a conclusion is provided in Section 5.

\section{2- Problem Description}

\section{2-1- Excitation System of Large Synchronous Motor}

For a large synchronous motor, the power supply to the stator is usually a medium voltage grid, $6 \mathrm{kV}$. The excitation source for the motor is usually a low voltage grid, $380 \mathrm{~V}$, which is lowered to the appropriate voltage level through a rectifier transformer. This power supply is then rectified to direct current to supply excitation current to the motor. To stabilize the working mode of the motor, the power factor stabilization plays a crucial role. Therefore, an excitation controller is designed aiming to stabilize the power factor $\cos \varphi$. The block diagram of the excitation control system for a synchronous motor is shown in Figure 1.

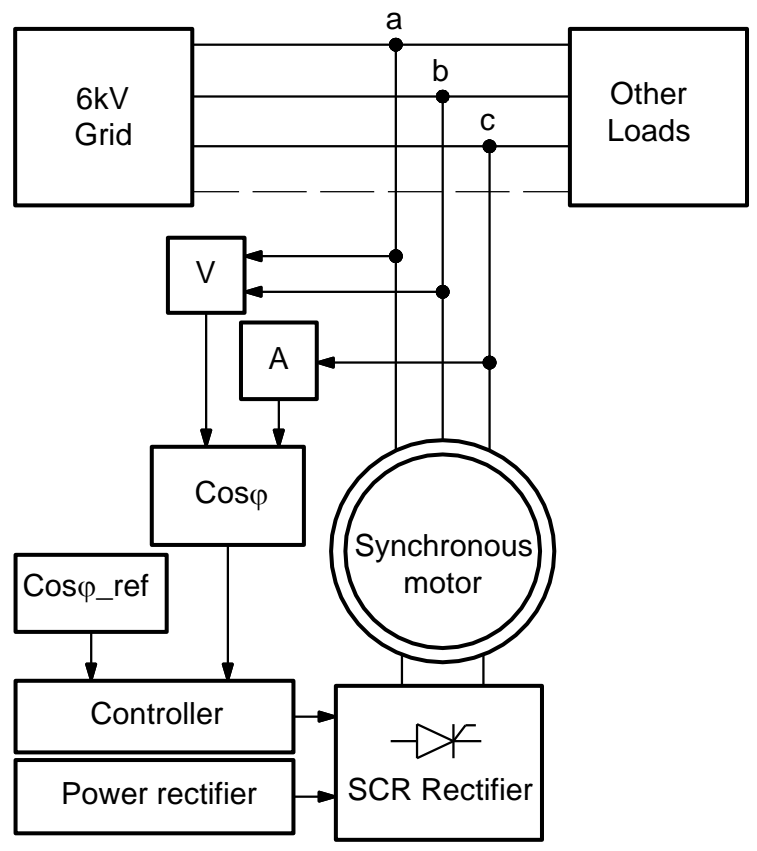

Figure 1. Block diagram of excitation control for synchronous motor

The phase difference between voltage and current is measured and compared to a desired $\cos \varphi$. The controller then calculates a control signal, which is sent to the rectifier to adjust the excitation current in order to achieve the desired power factor. To ensure favorable measurement of the phase difference between voltage and current, the stator windings of the synchronous motor can be star or delta connected to the grid. A typical power factor measurement method is to measure the angle of the voltage between two phases and the current of the other phase, as shown in Figure 2. The figure demonstrates that $u_{a b}$ is $90^{\circ}$ earlier earlier than $u_{\mathrm{c}}$. Therefore, when calculating the phase 
difference angle between voltage and current, $\varphi$, the stator must shift the angle of $u_{s a b}$ by an angle of $90^{\circ}$ to coincide with the angle of $u_{s c}$.

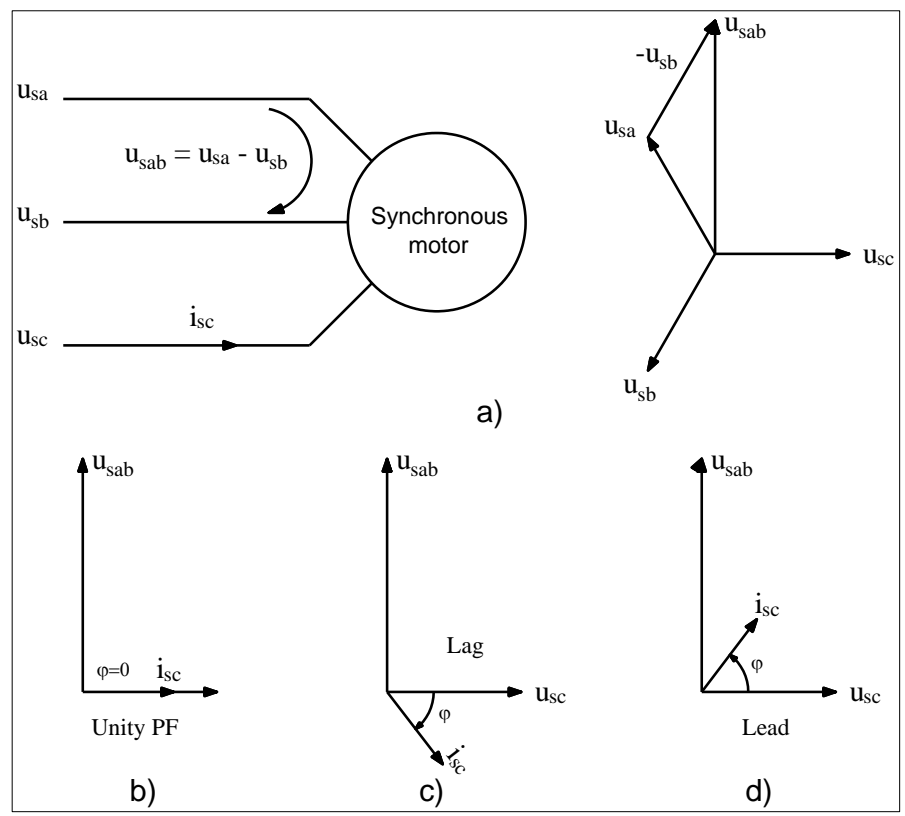

Figure 2. Vector diagram of stator current and voltage: (a) Vector diagram of stator current; (b) current and voltage are in same phase; (c) current lags behind voltage in phase; and (d) current leads ahead of voltage in phase

\section{2-2- Motor Modelling}

In this section, the backgrounds of the synchronous motor modelling are presented to demonstrate the critical role of power factor regulation and stabilization.

\section{2-2-1- Motor Equations and Equivalent Circuits}

Figure 3 shows a two-axis salient pole synchronous motor in a rotor coordinate system. The frame for stator windings, $(\alpha, \beta)$, is stationary with the real axis attached to the stator phase A. Meanwhile, the frame for the excitation and the damper windings, $(d, q)$, is rotating with the real axis fixed to the center of the pole shoe.

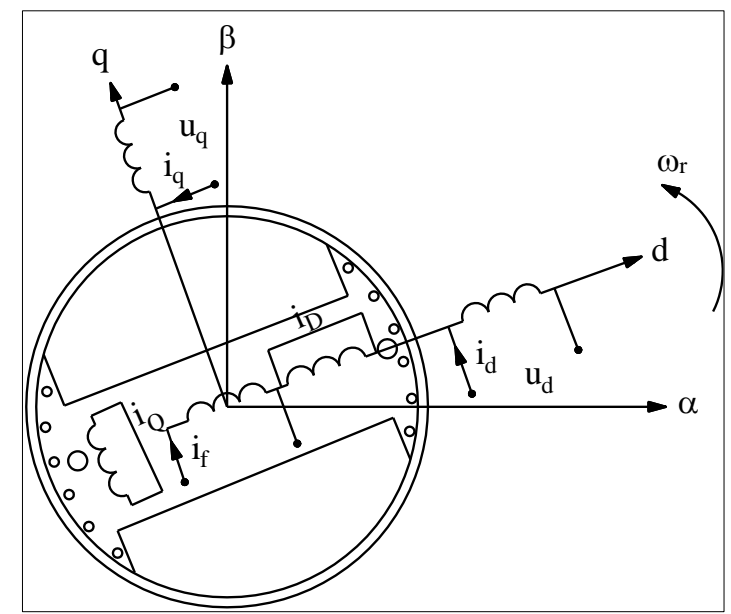

Figure 3. Two-axis salient pole synchronous motor model in the rotor coordinate systems

This coordinate system rotates with the rotor angular velocity, so both $d$-and $q$ - magnetic paths are constant. The excitation winding, $(f)$, is attached on the $d$-axis. The damper winding is replaced by two windings in space quadrature, one on the $d$-axis, $(D)$, and the other on the q-axis $(Q)$. The stator three-phase winding is also replaced by two windings in perpendicular space, on the $d$-axis, $(d)$, and on the $q$-axis $(q)$. The electrical equations of the motor are given as [25]:

$\mathrm{u}_{\mathrm{d}}=\mathrm{R}_{\mathrm{s}} \mathrm{i}_{\mathrm{d}}+\frac{\mathrm{d} \psi_{\mathrm{sd}}}{\mathrm{dt}}-\omega_{\mathrm{r}} \psi_{\mathrm{sq}}$

$u_{q}=R_{s} i_{q}+\frac{d \psi_{s q}}{d t}+\omega_{r} \psi_{s d}$ 


$$
\begin{aligned}
& u_{f}=R_{f} i_{f}+\frac{d \psi_{f}}{d t} \\
& u_{D}=R_{D} i_{D}+\frac{d \psi_{D}}{d t}=0 \\
& u_{Q}=R_{Q} i_{Q}+\frac{d \psi_{Q}}{d t}=0
\end{aligned}
$$

where $u_{d}$ is the d-axis stator voltage, $u_{q}$ is the q-axis stator voltage, $u_{f}$ is the excitation voltage, $u_{D}$ is the d-axis damper winding voltage, $u_{Q}$ is the q-axis damper winding voltage, $i_{d}$ is the d-axis stator current, $i_{q}$ is the q-axis stator current, $i_{f}$ is the excitation current, $i_{D}$ is the d-axis damper winding current, $i_{Q}$ is the q-axis damper winding current, $\psi_{d}$ is the daxis stator flux linkage, $\psi_{q}$ is the q-axis stator flux linkage, $\psi_{f}$ is the excitation flux linkage, $\psi_{D}$ is the d-axis damper winding flux linkage, $\psi_{Q}$ is the q-axis damper winding flux linkage, $\omega_{r}=\frac{d \theta}{d t}$ is the angular velocity between the rotor coordinates and the stationary reference frame $\alpha, \beta, \theta_{r}$ is the angle between the rotor coordinates and the stationary reference frame. The relationship between the motor currents and flux linkages can be defined by using various inductances of the motor [25]:

$$
\begin{aligned}
& \psi_{\mathrm{sd}}=\psi_{\mathrm{md}}+\mathrm{i}_{\mathrm{d}} \mathrm{L}_{\mathrm{s} \sigma}=\mathrm{L}_{\mathrm{md}}\left(\mathrm{i}_{\mathrm{f}}+\mathrm{i}_{\mathrm{d}}+\mathrm{i}_{\mathrm{D}}\right)+\mathrm{i}_{\mathrm{d}} \mathrm{L}_{\mathrm{s} \sigma} \\
& \psi_{\mathrm{sq}}=\psi_{\mathrm{mq}}+\mathrm{i}_{\mathrm{d}} \mathrm{L}_{\mathrm{s} \sigma}=\mathrm{L}_{\mathrm{mq}}\left(\mathrm{i}_{\mathrm{q}}+\mathrm{i}_{\mathrm{Q}}\right)+\mathrm{i}_{\mathrm{q}} \mathrm{L}_{\mathrm{s} \sigma} \\
& \psi_{\mathrm{f}}=\psi_{\mathrm{md}}+\mathrm{i}_{\mathrm{f}} \mathrm{L}_{\mathrm{f} \sigma}+\left(\mathrm{i}_{\mathrm{f}}+\mathrm{i}_{\mathrm{D}}\right) \mathrm{L}_{\mathrm{k} \sigma}=\mathrm{L}_{\mathrm{md}}\left(\mathrm{i}_{\mathrm{d}}+\mathrm{i}_{\mathrm{D}}+\mathrm{i}_{\mathrm{f}}\right)+\left(\mathrm{i}_{\mathrm{f}}+\mathrm{i}_{\mathrm{D}}\right) \mathrm{L}_{\mathrm{k} \sigma}+\mathrm{i}_{\mathrm{f}} \mathrm{L}_{\mathrm{f} \sigma} \\
& \psi_{\mathrm{D}}=\psi_{\mathrm{md}}+\mathrm{i}_{\mathrm{D}} \mathrm{L}_{\mathrm{D} \sigma}+\left(\mathrm{i}_{\mathrm{f}}+\mathrm{i}_{\mathrm{D}}\right) \mathrm{L}_{\mathrm{k} \sigma}=\mathrm{L}_{\mathrm{md}}\left(\mathrm{i}_{\mathrm{d}}+\mathrm{i}_{\mathrm{D}}+\mathrm{i}_{\mathrm{f}}\right)+\left(\mathrm{i}_{\mathrm{f}}+\mathrm{i}_{\mathrm{D}}\right) \mathrm{L}_{\mathrm{k} \sigma}+\mathrm{i}_{\mathrm{D}} \mathrm{L}_{\mathrm{D} \sigma} \\
& \psi_{\mathrm{Q}}=\psi_{\mathrm{mq}}+\mathrm{i}_{\mathrm{Q}} \mathrm{L}_{\mathrm{Q} \sigma}=\mathrm{L}_{\mathrm{md}}\left(\mathrm{i}_{\mathrm{q}}+\mathrm{i}_{\mathrm{Q}}\right)+\mathrm{i}_{\mathrm{Q}} \mathrm{L}_{\mathrm{Q} \sigma}
\end{aligned}
$$

where $L_{m d}$ is the d-axis magnetising inductance, $L_{s} \sigma$ is the stator leakage inductance, $L_{D \sigma}$ is the d-axis damper winding leakage inductance, $L_{f \sigma}$ is the magnetising winding leakage inductance, $L_{k} \sigma$ is the d-axis Canay inductance, $L_{m q}$ is the qaxis magnetising inductance, $L_{Q \sigma}$ is the q-axis damper winding leakage inductance, $R_{s}$ is the stator resistance, $R_{f}$ is the magnetising winding resistance, $R_{D}$ is the d-axis damper winding resistance, and $R_{Q}$ is the q-axis damper winding resistance. From Equations 1 to 10, the equivalent circuits of a synchronous motor can be obtained, as illustrated in Figures 4 and 5:

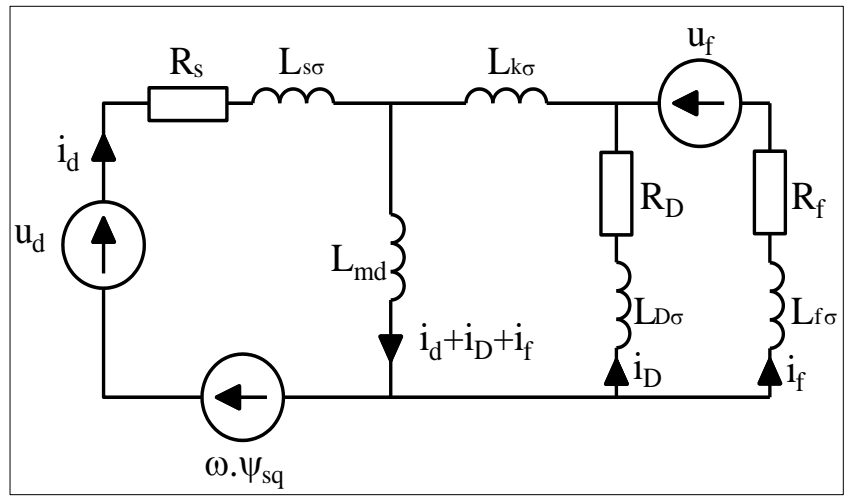

Figure 4. Equivalent circuits of the synchronous motor on the d- axis

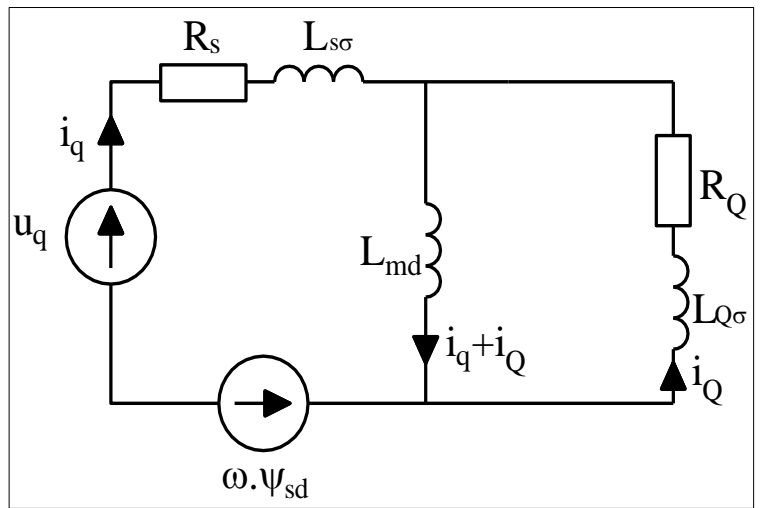

Figure 5. Equivalent circuits of the synchronous motor on the q- axis 


\section{2-2-2- Vector Diagram of a Synchronous Motor}

From Equations 1 to 10, the vector diagram of the salient pole synchronous motor is built as shown in Figure 6

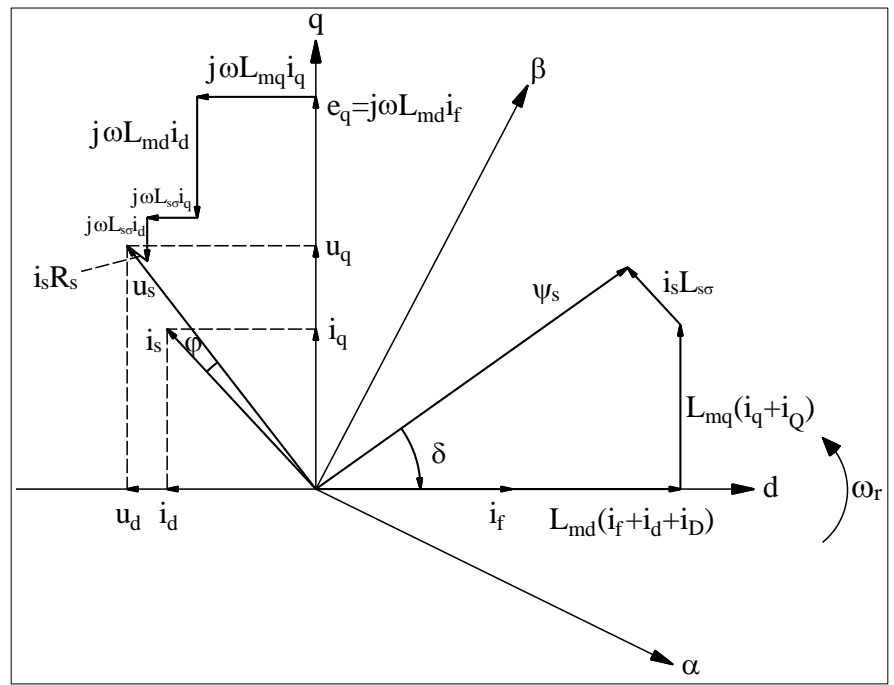

Figure 6. Vector diagram of the salient pole synchronous motor

In fact, the stator resistance is usually minimal compared to its inductance. Therefore, the voltage drop across the stator resistor can be ignored. The total inductances in the machine are denoted as:

$\mathrm{L}_{\mathrm{sd}}=\mathrm{L}_{\mathrm{s} \sigma}+\mathrm{L}_{\mathrm{md}}$

$\mathrm{L}_{\mathrm{sq}}=\mathrm{L}_{\mathrm{s} \sigma}+\mathrm{L}_{\mathrm{mq}}$

$\mathrm{X}_{\mathrm{sd}}=\omega \mathrm{L}_{\mathrm{sd}}$

$\mathrm{X}_{\mathrm{sq}}=\omega \mathrm{L}_{\mathrm{sq}}$

where $X_{s d}$ and $X_{s q}$ are corresponding d- and q-axis stator reactances. From Equations 11 and 12, and Figure 6, assuming that voltage drop on $R_{s}$ is ignored, we obtain:

$$
\begin{aligned}
& \mathrm{u}_{\mathrm{d}}=\mathrm{j}\left(\omega \mathrm{L}_{\mathrm{mq}}+\omega \mathrm{L}_{\mathrm{s} \sigma}\right) \mathrm{i}_{\mathrm{q}}=\omega \mathrm{L}_{\mathrm{sq}} \mathrm{i}_{\mathrm{q}}=\mathrm{j} \mathrm{X}_{\mathrm{sq}} \mathrm{i}_{\mathrm{q}} \\
& \mathrm{u}_{\mathrm{q}}=\mathrm{e}_{\mathrm{q}}+\mathrm{j}\left(\omega \mathrm{L}_{\mathrm{md}}+\omega \mathrm{L}_{\mathrm{s} \sigma}\right) \mathrm{i}_{\mathrm{d}}=\mathrm{e}_{\mathrm{q}}+\mathrm{j} \omega \mathrm{L}_{\mathrm{sd}} \mathrm{i}_{\mathrm{d}}=\mathrm{e}_{\mathrm{q}}+\mathrm{j} \mathrm{X}_{\mathrm{sd}} \mathrm{i}_{\mathrm{d}} \\
& \mathrm{u}_{\mathrm{s}}=\mathrm{u}_{\mathrm{d}}+\mathrm{u}_{\mathrm{q}}=\mathrm{e}_{\mathrm{q}}+\mathrm{j} \mathrm{X}_{\mathrm{sd}} \mathrm{i}_{\mathrm{d}}+\mathrm{j} \mathrm{X}_{\mathrm{sq}} \mathrm{i}_{\mathrm{q}}=\mathrm{e}_{\mathrm{q}}+\mathrm{j} \mathrm{X}_{\mathrm{s}} \mathrm{i}_{\mathrm{s}}
\end{aligned}
$$

where $X_{s}$ is the stator reactance. From Equations 15 to 17 , a simplified vector diagram can be then constructed as shown in Figure 7, with the angle between the voltage vector, $u_{s}$, and the q-axis electromotive force, $e_{q}$, being the load angle $\delta$.

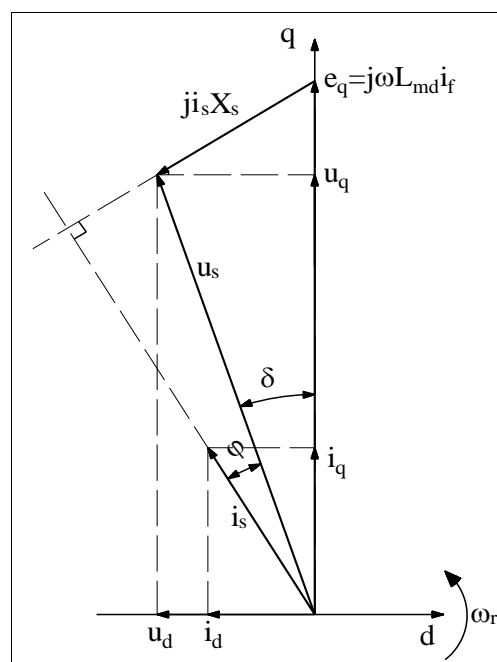

(a)

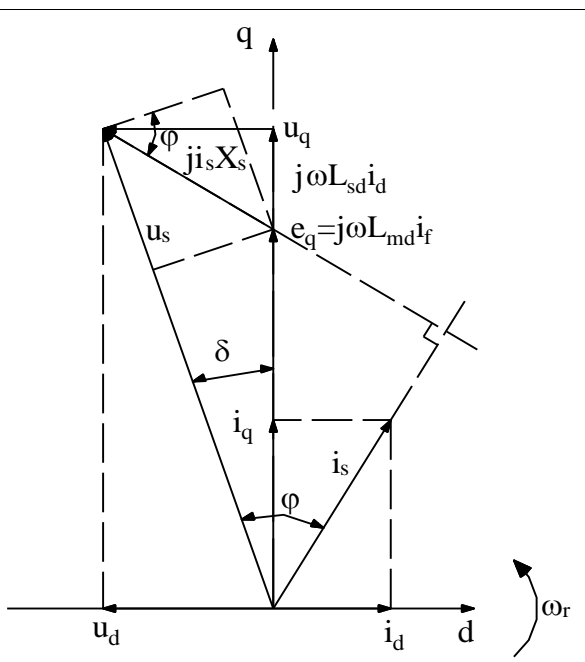

(b)

Figure 7. Vector diagram of a synchronous motor in steady-state mode when stator winding resistance is ignored, with $X_{s}=$ $\omega L_{s}$ : (a) Current leads of voltage in phase, and (b) Current lags behind voltage in phase 
According Figure 7-b, we have:

$\mathrm{I}_{\mathrm{s}} \mathrm{X}_{\mathrm{s}} \cos \varphi=\mathrm{E}_{\mathrm{q}} \sin \delta$,

Accordingly,

$\mathrm{U}_{\mathrm{s}} \mathrm{I}_{\mathrm{s}} \cos \varphi=\frac{\mathrm{U}_{\mathrm{s}} \mathrm{E}_{\mathrm{q}} \sin \delta}{\mathrm{X}_{\mathrm{s}}}$.

where $U_{s}$ and $I_{s}$ are corresponding amplitude of stator voltage and current, $E_{q}$ is the amplitude of excitation electromotive force, and $\mathrm{X}_{\mathrm{s}}=\omega \mathrm{L}_{\mathrm{s}}$ is the stator reactance. The electromagnetic power of the motor, ignoring the losses, is given as [26-30]:

$\mathrm{P}_{\mathrm{e}}=\mathrm{P}_{\mathrm{m}}=\frac{3}{2} \mathrm{U}_{\mathrm{s}} \mathrm{I}_{\mathrm{s}} \cos \varphi$,

where $P_{e}$ and $P_{m}$ are corresponding the electromagnetic power and motor power. From Equations 19 and 20 , we obtain:

$\mathrm{P}_{\mathrm{e}}=\mathrm{P}_{\mathrm{m}}=\frac{3}{2} \mathrm{U}_{\mathrm{s}} \mathrm{I}_{\mathrm{s}} \cos \varphi=\frac{3}{2} \frac{\mathrm{U}_{\mathrm{s}} \mathrm{E}_{\mathrm{q}} \sin \delta}{\mathrm{X}_{\mathrm{s}}}$

Equation 21 shows the relationship between power and excitation voltage and load angle. Assuming the source voltage and frequency are constant, we will have the following relationship:

$P_{e}=P_{m}=f\left(I_{s} \cos \varphi\right)$

$P_{e}=P_{m}=f\left(E_{q} \sin \delta\right)$

\section{2-2-3- Torque equation of synchronous motor at steady state}

From the vector diagram in Figure 7-b, we have:

$\mathrm{I}_{\mathrm{s}} \cos \varphi=\mathrm{I}_{\mathrm{q}} \cos \delta-\mathrm{I}_{\mathrm{d}} \sin \delta$,

We can also compute:

$I_{d}=\frac{U_{q}-E_{q}}{\omega L_{s d}}=\frac{U_{s} \cos \delta-E_{q}}{\omega L_{s d}}$,

$\mathrm{I}_{\mathrm{q}}=\frac{\mathrm{U}_{\mathrm{s}} \sin \delta}{\omega \mathrm{L}_{\mathrm{sq}}}$

Substituting Equations 24 to 26 into equation 20, we obtain a second method to determine the electromagnetic power of the motor in working mode as:

$\mathrm{P}_{\mathrm{e}}=\frac{3}{2} \frac{\mathrm{U}_{\mathrm{s}} \mathrm{E}_{\mathrm{q}}}{\omega \mathrm{L}_{\mathrm{sd}}} \cdot \sin \delta+\frac{3}{2} \mathrm{U}_{\mathrm{s}}^{2} \frac{\left(\mathrm{L}_{\mathrm{sd}}-\mathrm{L}_{\mathrm{sq}}\right)}{\omega \mathrm{L}_{\mathrm{sd}} \mathrm{L}_{\mathrm{sq}}} \cdot \sin 2 \delta$.

The electromagnetic torque in working mode is calculated as:

$\mathrm{T}_{\mathrm{e}}=\frac{\mathrm{P}_{\mathrm{e}} \mathrm{p}_{\mathrm{r}}}{\omega}=\frac{3 \mathrm{p}_{\mathrm{r}}}{2 \omega}\left[\frac{\mathrm{U}_{\mathrm{s}} \mathrm{E}_{\mathrm{q}}}{\omega \mathrm{L}_{\mathrm{sd}}} \cdot \sin \delta+\mathrm{U}_{\mathrm{s}}^{2} \frac{\left(\mathrm{L}_{\mathrm{sd}}-\mathrm{L}_{\mathrm{sq}}\right)}{\omega \mathrm{L}_{\mathrm{sd}} \mathrm{L}_{\mathrm{sq}}} \cdot \sin 2 \delta\right]$.

Since $\omega \mathrm{L}=\mathrm{X}$, Equation 28 can be rewritten as:

$\mathrm{T}_{\mathrm{e}}=\frac{3 \mathrm{p}_{\mathrm{r}}}{2 \omega}\left[\frac{\mathrm{U}_{\mathrm{s}} \mathrm{E}_{\mathrm{q}}}{\mathrm{X}_{\mathrm{sd}}} \cdot \sin \delta+\mathrm{U}_{\mathrm{s}}^{2} \frac{\left(\mathrm{X}_{\mathrm{sd}}-\mathrm{X}_{\mathrm{sq}}\right)}{\mathrm{X}_{\mathrm{sd}} \mathrm{X}_{\mathrm{sq}}} \cdot \sin 2 \delta\right]$.

In the steady state, the electromagnetic torque of a salient pole synchronous motor has two components. The first part is the main synchronous torque, which depends on the AC voltage and excitation source, $\mathrm{U}_{\mathrm{s}} \mathrm{E}_{\mathrm{q}}$. The second component is the reluctance torque which depends only on the stator voltage, $\mathrm{U}_{\mathrm{s}}{ }^{2}$. Figure 8 depicts the torque-load angle characteristics of a salient pole synchronous motor, where $T_{1}(\delta)$ is the main synchronous torque, $T_{1}(\delta)$ is the reluctance synchronous torque, and $\mathrm{T}_{\mathrm{e}}(\delta)$ is the total synchronous torque. 


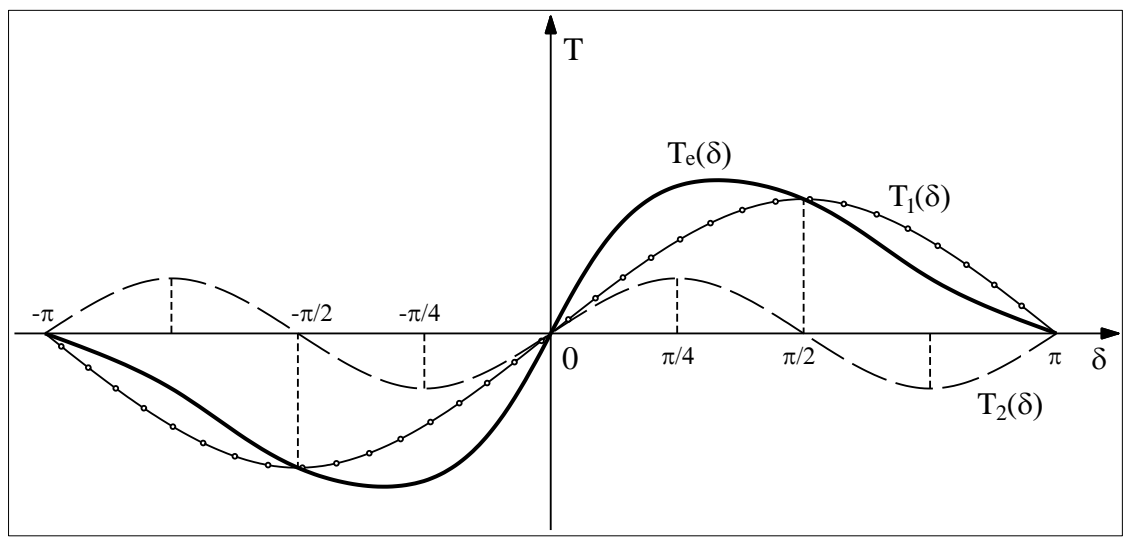

Figure 8. Torque-load angle characteristics of a salient pole synchronous motor

From Equation 29, torque regulation is critical so that the motor remains to work safely in the face of a voltage drop of the mains voltage or overload of the torque. To control the torque, we can adjust the field current, resulting in changing $\mathrm{T}_{1}(\delta)$, which is the main synchronous torque.

\section{2-3- Factors Affecting the Working Mode of the Motor}

For a large synchronous motor, the fluctuation of the load in the operating mode can cause the load angle $\delta$ to change accordingly. An excessive change can cause an asynchronous phenomenon, i.e., the rotor magnetic pole slips from the stator magnetic pole. A change in the excitation source can also affect the operating mode of the motor. This section will discuss these effects, in which the load angle, $\delta$, and the current-voltage phase difference, $\varphi$, are used to evaluate the operating mode of the motor.

\section{2-3-1- Vector Diagram of a Synchronous Motor}

To make it easier to follow, we rotate the coordinate system of the vector diagram so that $u_{s}$ coincides with the horizontal axis. Assume that the power supply, the power grid frequency, and the DC excitation source are constant. The vector diagram after rotation, in case of load change, is shown in Figure 9.

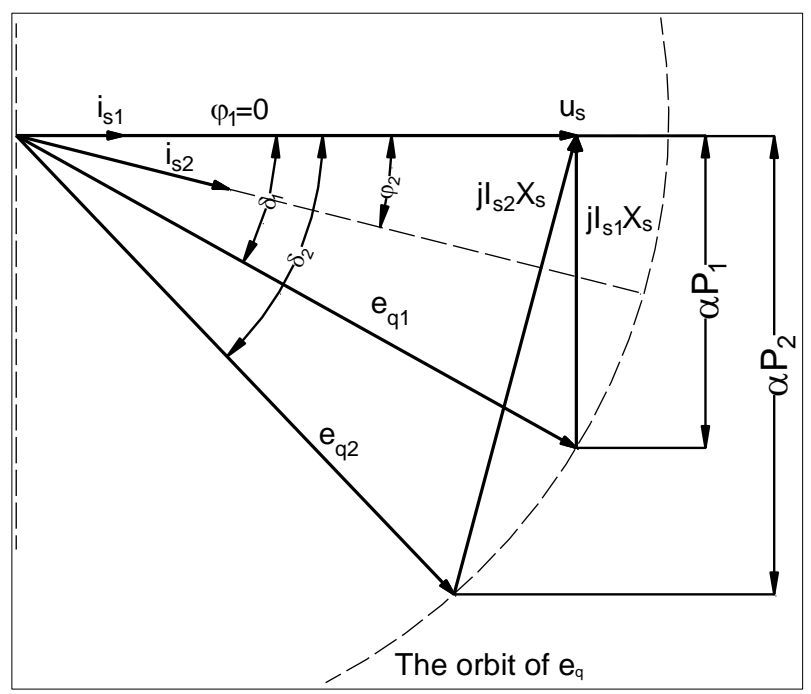

Figure 9. Vector diagram of synchronous motor when stator source and excitation source are constant, load changes from $P_{1}$ to $\mathbf{P}_{2}$, with $\mathbf{P}_{2}>\mathbf{P}_{1}$

According to Figure 9, the motor is initially assumed to work with stator current $i_{s l}$, power $\alpha P_{l}$, where $\alpha$ is a constant, power factor $\cos \varphi \approx 1$. When the load on the motor shaft increases to $\alpha P_{2}$, the armature current will increase to the value $i_{s 2}$. Assuming the excitation source is constant, its trajectory will draw an arc. Then, the phase difference angle $\varphi$ increases in the positive direction, $\cos \varphi$ decrease, load angle increases, i.e., $\delta_{2}>\delta_{I}$. When the load $\delta$ increases within a permissible range, the stator magnetic field can still lock the rotor magnetic field, so the motor speed remains unchanged. However, if the load increases sharply, $\delta_{2}$ tends to go to $-90^{\circ}$. At this time, the motor is pulled out of synchronous mode. Therefore, the excitation controller must detect a decrease in the power factor to increase the field current to a suitable value to pull the motor into synchronous mode. 


\section{2-3-2- The Influence of the Excitation Source}

From Equation 21, if the load and $\mathrm{AC}$ source are fixed, then $E_{q} \sin \delta$ is also a constant. Therefore, when increasing the excitation source $E_{q}$, the load angle will decrease. This causes the relative angular position between the rotor and stator magnetic fields to decrease, the stator magnetic poles will be more tightly attached to the rotor, and the motor will run at synchronous speed. The vector diagram when changing the excitation source value is illustrated in Figure 10 , therein the subscript $\{1,2,3\}$ are corresponding to three different excitation source values:

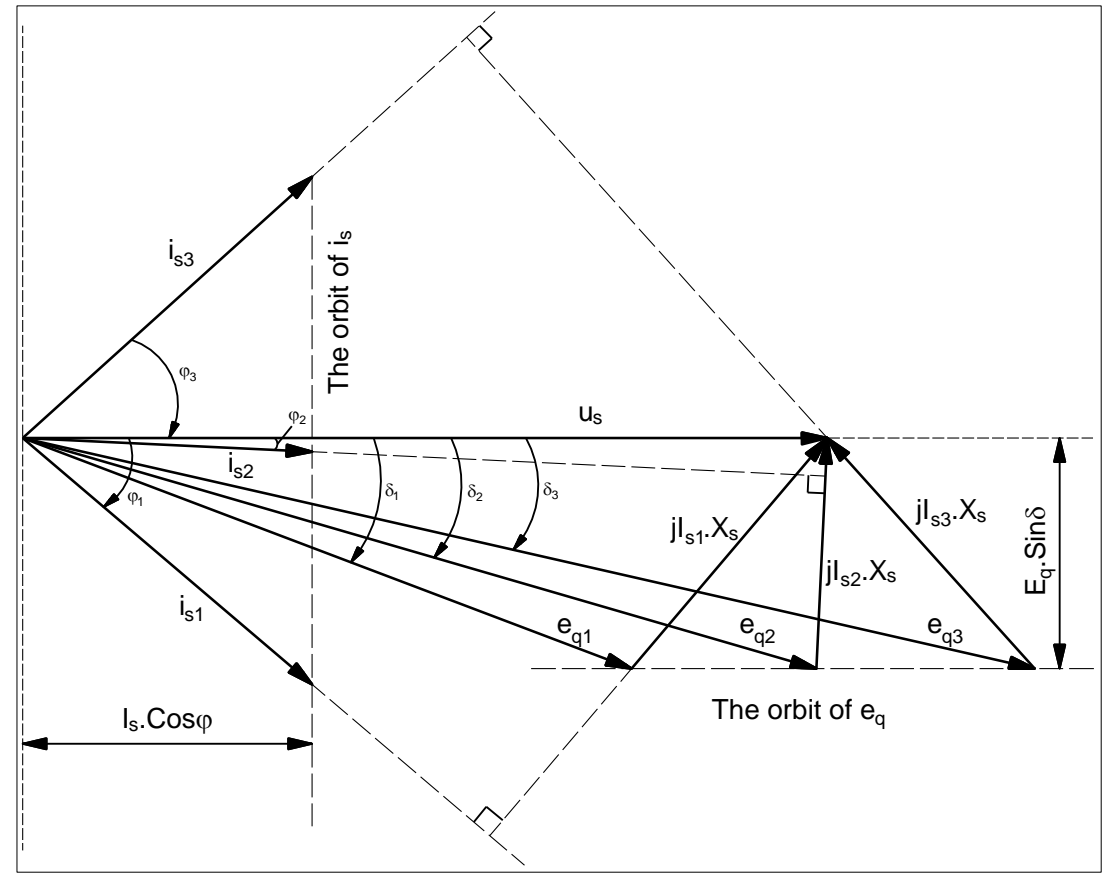

Figure 10. The influence of the excitation source on the working mode

According to Equation 21, with a fixed load, we have:

$\mathrm{E}_{\mathrm{q} 1} \sin \delta_{1}=\mathrm{E}_{\mathrm{q} 2} \sin \delta_{2}=\mathrm{E}_{\mathrm{q} 3} \sin \delta_{3}=\mathrm{E}_{\mathrm{q}} \sin \delta$.

From Equation 30 and Figure 10 we see that the trajectory of $\mathrm{E}_{\mathrm{q}}$ will slide parallelly to $\mathrm{u}_{\mathrm{s}}$. Also, from Equation 21 , we have:

$\mathrm{I}_{\mathrm{s} 1} \cos \varphi_{1}=\mathrm{I}_{\mathrm{s} 2} \cos \varphi_{2}=\mathrm{I}_{\mathrm{s} 3} \cos \varphi_{3}=\mathrm{I}_{\mathrm{s}} \cos \varphi$.

From Equation 31 and Figure 10 we see that the trajectory of $i_{s}$ will slide perpendicular to $u_{s}$. Increasing the excitation source from $E_{q 1}$ to $E_{q 3}$ causes the phase angle of the current with voltage to change from phase lag state to phase lead state. The value of the excitation source that produces the normal power factor is called the normal excitation. Excitement higher than the normal value is typically called over-excitation. In this scenario, the motor works as a synchronous compensator. Excitement lower than the normal value is called under-excitation. In this case, the engine works like an asynchronous machine. The above analysis shows that power factor correction is beneficial in applications where the motor is subjected to high transient loads. The power factor regulator must measure the power factor drop that occurs when the motor is subjected to a sudden heavy load and send a signal to the thyristor static rectifier to increase the value of the excitation source. This process is called excitation enhancement. As a result, the pull-out torque of the synchronous motor is increased during transient loads. After the load drops, the regulator senses the excessive lead-in power factor and drives the rectifier to drop the voltage at its output. Another application of the power factor regulator is to control the variation of the plant power factor caused by other loads such as asynchronous motor running under or no load, thereby improving the voltage quality of the plant.

\section{3- PSO-Based Hybrid PID-FLC Sugeno Control Design}

\section{3-1- PSO Preliminaries}

The PSO optimization algorithm is a random search algorithm based on simulating the behavior and interaction of birds when looking for food sources. Each bird, called individual or element, in the flock, called population, is characterized by two components, the position vector $x_{i}$ and the velocity vector $v_{i}$. Each individual has a fitness value, which is assessed by the fitness function. Initially, the PSO has initialized random position and velocity vectors [31- 
34]. Then in each iteration of the algorithm, the velocity vector $v_{i}$ and the position $x_{i}$ of each individual will be updated as:

$$
\begin{aligned}
& \mathrm{v}_{\mathrm{i}}(\mathrm{k}+1)=\omega(\mathrm{k}) \mathrm{v}_{\mathrm{i}}(\mathrm{k})+\mathrm{c}_{1} \mathrm{r}_{1}\left(\mathrm{P}_{\mathrm{i}}(\mathrm{k})-\mathrm{x}_{\mathrm{i}}(\mathrm{k})\right)+\mathrm{c}_{2} \mathrm{r}_{2}\left(\mathrm{G}(\mathrm{k})-\mathrm{x}_{\mathrm{i}}(\mathrm{k})\right), \\
& \mathrm{x}_{\mathrm{i}}(\mathrm{k}+1)=\mathrm{x}_{\mathrm{i}}(\mathrm{k})+\mathrm{v}_{\mathrm{i}}(\mathrm{k}+1),
\end{aligned}
$$

where $k$ repesents the iteration; $\omega(k)$ is a weight parameter; $c_{1}$ and $c_{2}$ are corresponding cognitive and social parameter, $r_{l}$ and $r_{2}$ are random samples in the interval [0;1]. At each iteration, each individual is influenced by the best position it has achieved, $P_{i}(k)$, and the global best position in all searches by all individuals in population, $G(k)$. In this paper, PSO will be implemented to find the optimal parameters for a hybrid PID-FLC Sugeno control design for the excitation system of a large synchronous motor. The "particleswarm()" function in MATLAB software was used to perform the PSO algorithm.

\section{3-2- Hybrid PID-FLC Sugeno Control Design for Excitation System of Large Synchronous Motor}

The structure diagram of the excitation control system, using hybrid PID-FLC Sugeno control, is shown in Figure 11. In this diagram, the object consists of a three-phase 6 pulse bridge rectifier and the synchronous motor. The output voltage of the rectifier will provide a field source for the rotor windings. The power factor $\cos \varphi$ is measured at the stator side of the motor and compared with the setpoint. The error $e(t)$ is fed to the PID controller for processing. The fuzzy controller receives the error signal $e(t)$ and its derivative to process according to the established composition rule. The output signal of the PID controller and fuzzy logic controller is added and sent to the thyristor excitation regulator to change the DC output voltage of the rotor winding.

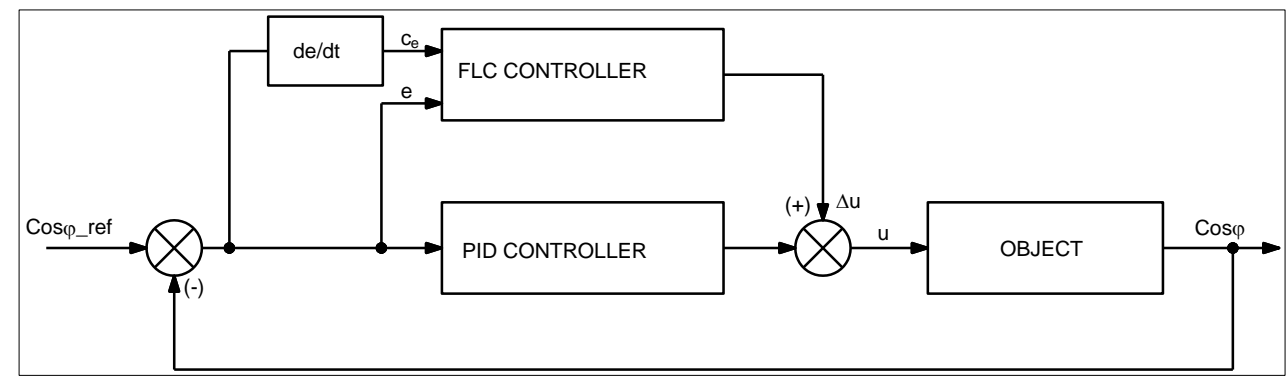

Figure 11. Hybrid PID-FLC Sugeno controller

\section{3-3- PSO-Based PID Controller}

At the first step, a PID controller is designed as shown in Figure 12. The feedback control signal is computed as:

$$
\mathrm{u}(\mathrm{s})=\mathrm{e}(\mathrm{s})\left[\mathrm{K}_{\mathrm{p}}+\mathrm{K}_{\mathrm{i}} \frac{1}{\mathrm{~s}}+\mathrm{K}_{\mathrm{d}} \frac{\mathrm{K}_{\mathrm{N}}}{1+\mathrm{K}_{\mathrm{N}} \frac{1}{\mathrm{~s}}}\right] \text {, }
$$

where $K_{p}, K_{i}, K_{d}$ are corresponding coefficients for proportional, integral, and derivative terms, $K_{N}$ is the filter coefficient. These coefficients are components of the optimal variable set up for the PSO algorithm. The fitness function of the PSO is selected using the integral absolute error (IAE) index as:

$\mathrm{IAE}=\sum_{\mathrm{k}=1}^{\mathrm{n}}|\mathrm{e}(\mathrm{k})|$,

where $e(k)$ is the error at $k$-iteration, $n$ is the total number of samples in an iteration.

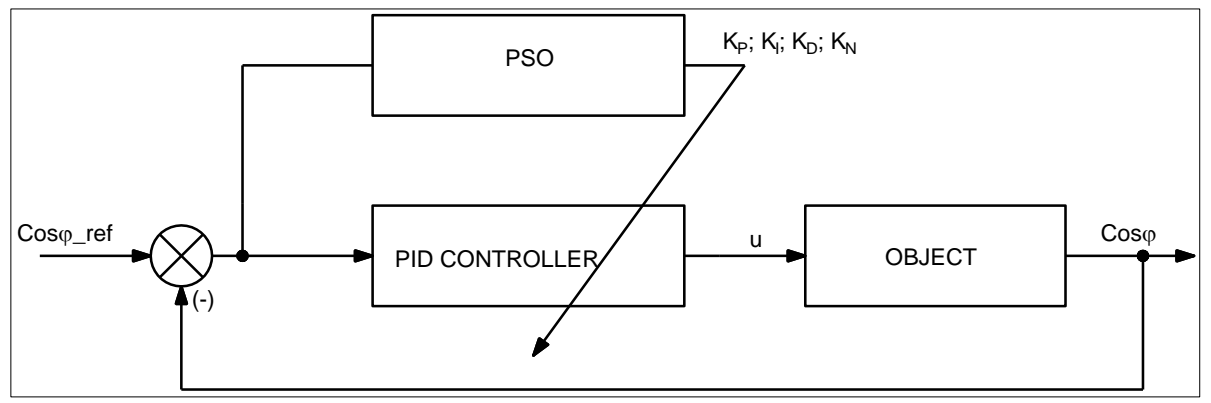

Figure 12. PSO-based PID controller 


\section{3-4- PSO-Based Hybrid PID-FLC Sugeno Controller}

In this section, a hybrid PID-FLC Sugeno controller is designed to control excitation for the synchronous motor so that the power factor tracks its desired value. The structure of a hybrid controller is shown in Figure 13, therein the modulating signal offset $\Delta_{u}$ for the PID controller is obtained from the output of the fuzzy controller. The PID parameters are optimized using the PSO algorithm as presented in Section 3-3.

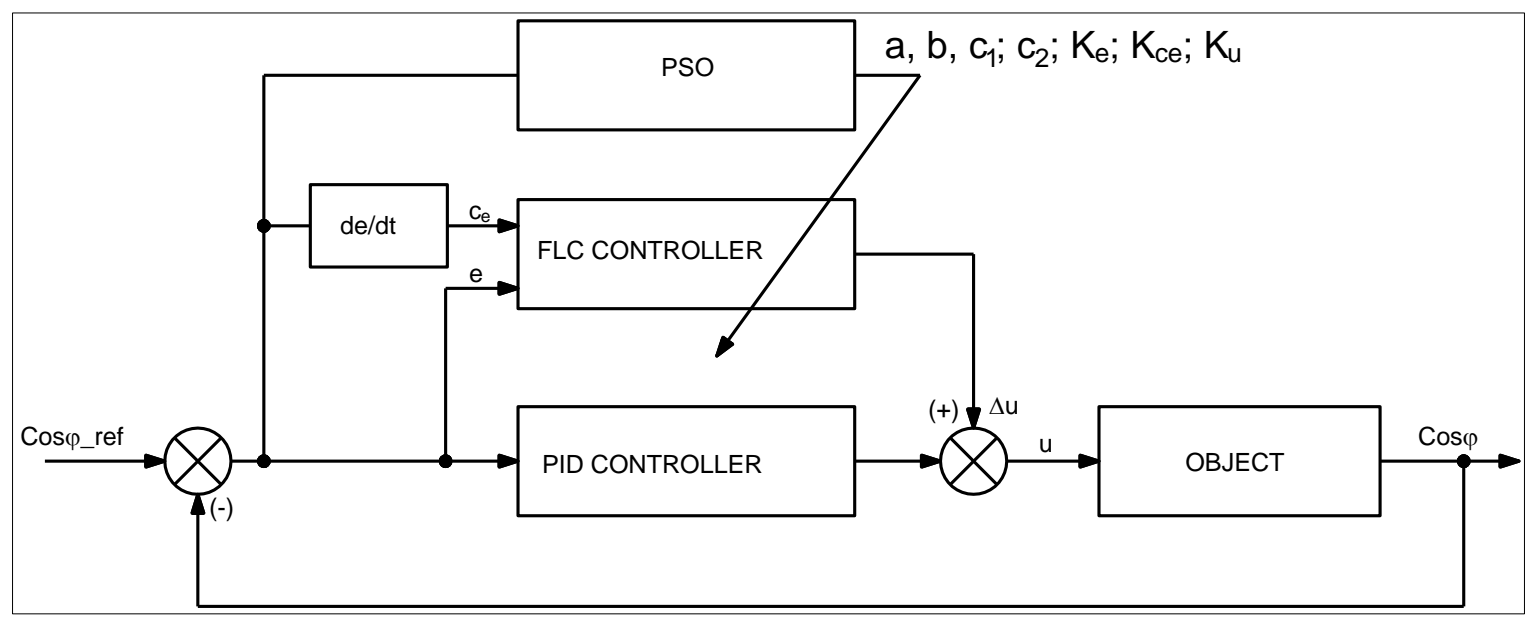

Figure 13. PSO-based hybrid PID-FLC Sugeno controller

The FLC Sugeno controller is designed with two input variables, the error $e$ and its derivatives $c e$, and one output variable, $\Delta u$. The range of these inputs/outputs is defined in the symmetric normal domain as $[-1,1]$. When the controller is introduced into the system, the real variation domain will be corrected to the standard symmetry domain by the coefficients $K_{e}, K_{c e}$ and $K_{u}$. The selected fuzzy sets are designed with names denoted and interpreted as in Table 1 .

Table 1. Notation for fuzzy sets

\begin{tabular}{ccccccc}
\hline NB & N & NS & ZE & PS & P & PB \\
\hline Negative Big & Negative & Negative Small & Zero & Positive Small & Positive & Positive Big \\
\hline
\end{tabular}

There are 5 membership functions for input variables, $e$ and $c e$, including $N B, N S, Z E, P S, P B$. The membership functions are designed to be strongly fuzzy partitions, i.e., for any value of $x$, the total membership of $x$ on the membership function is equal to 1 . There are 7 membership functions for the output variable $\Delta u$, including $N B, N, N S$, $Z E, P S, P, P B$. The control rule system is designed as shown in Table 2 .

Table 2. FLC-sugeno control rule

\begin{tabular}{c|ccccc}
\hline e & NB & NS & ZE & PS & PB \\
\hline NB & NB & NB & N & NS & ZE \\
NS & NB & N & NS & ZE & PS \\
ZE & N & NS & ZE & PS & P \\
PS & NS & ZE & PS & P & PB \\
PB & ZE & PS & P & PB & PB \\
\hline
\end{tabular}

In order to adjust the shape of membership functions towards the optimal for the controller, in this study, some constraints are introduced to limit the number of variables to be optimized as follows:

- It is assumed that the partitioned membership functions are symmetric on the domain $[-1,1]$. It means that the membership function $Z E$ has the form of an isosceles triangle.

- The membership function $N B$ is symmetric to the $P B$ through the value 0 . Similarly, we have other symmetric membership functions over the zero point, $(N, P)$ and $(N S, P S)$. 
Thus, to build symmetric membership functions, we only need to adjust the values of points $a$ for variable $e, b$ for variable $c e$, and $c_{1}, c_{2}$ for variable $\Delta u$, as shown in Figure 14. Thus, to optimize FLC-sugeno fuzzy controller, we need to optimize 4 variables for membership functions. The search domain for variables is defined in the range: $a, b \in[0.25$, $0.75] ; c_{1} \in[0.25,0.45]$; and $c_{2} \in[0.45,0.75]$, represented by red lines in the figure. These variable are compoments of the optimal variable set for PSO algorithm, with a fitness function is chosen as Equation 35.

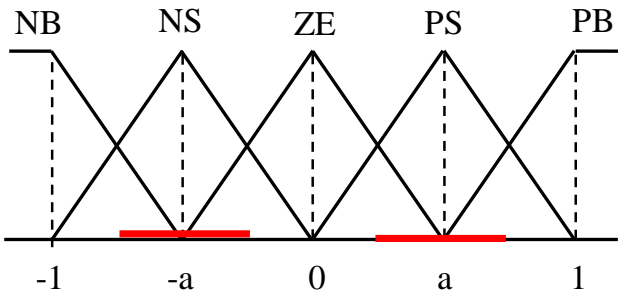

Membership functions of " $e$ "

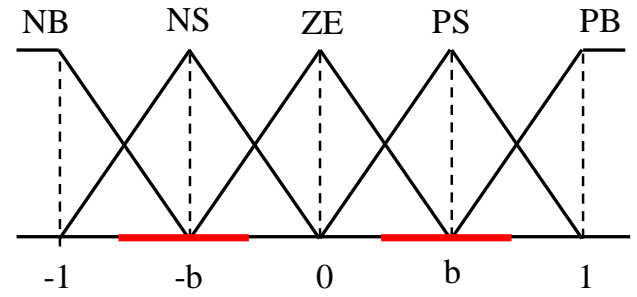

Membership functions of "ce"

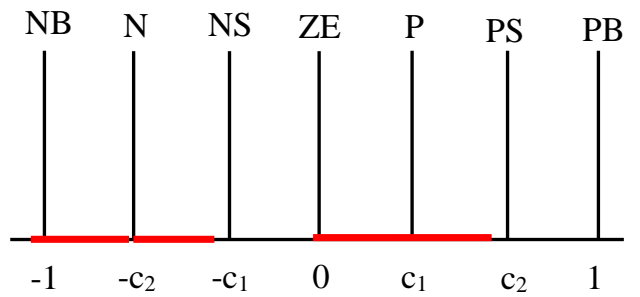

Membership functions of " $\Delta u^{\prime \prime}$

Figure 14. Optimizing the membership functions of the FLC-Sugeno controller using PSO

\section{4- Simulation Results}

In this section, simulation is carried out on a convex pole synchronous motor working in a steady-state in the present load change. The simulation diagram on Matlab/Simulink using the proposed PSO-based hybrid fuzzy control system is shown in Figure 15. The simulation parameters are given in Table 3.

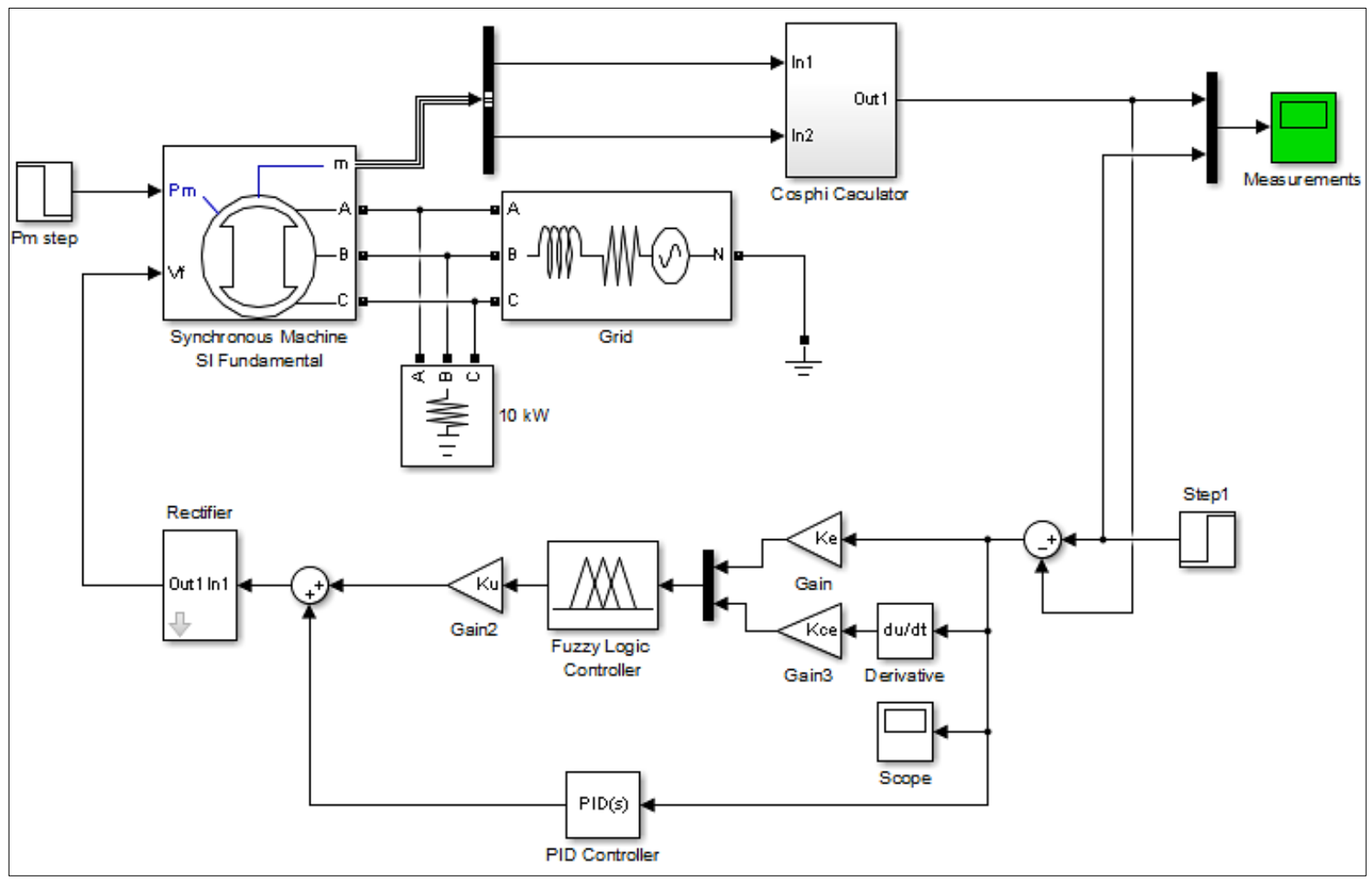

Figure 15. Control system on Matlab/Simulink 
Table 3. The simulation parameters

\begin{tabular}{lccc}
\hline \multicolumn{1}{c}{ Parameter } & Symbol & Value & Unit \\
\hline Stator resistance & $\mathrm{R}_{\mathrm{s}}$ & 0.26 & $\Omega$ \\
Stator leakage inductance & $\mathrm{L}_{\mathrm{s} \sigma}$ & 1.14 & $\mathrm{mH}$ \\
$d$-axis magnetising inductance & $\mathrm{L}_{\mathrm{md}}$ & 13.7 & $\mathrm{mH}$ \\
$q$-axis magnetising inductance & $\mathrm{L}_{\mathrm{mq}}$ & 11 & $\mathrm{mH}$ \\
d-axis damper winding resistance & $\mathrm{R}_{\mathrm{D}}$ & 0.0224 & $\Omega$ \\
$d$-axis damper winding leakage inductance & $\mathrm{L}_{\mathrm{D \sigma}}$ & 1.4 & $\mathrm{mH}$ \\
$q$-axis damper winding resistance & $\mathrm{R}_{\mathrm{Q}}$ & 0.02 & $\Omega$ \\
$q$-axis damper winding leakage inductance & $\mathrm{L}_{\mathrm{Q} \sigma}$ & 1 & $\mathrm{mH}$ \\
Number of pair of poles & $\mathrm{P}$ & 10 & - \\
Magnetising winding resistance & $\mathrm{R}_{\mathrm{f}}$ & 0.13 & $\Omega$ \\
Magnetising winding leakage inductance & $\mathrm{L}_{\mathrm{f} \sigma}$ & 2.1 & $\mathrm{mH}$ \\
Rate stator current of phase A & $\mathrm{I}_{\mathrm{a}}$ & 53.9 & $\mathrm{~A}$ \\
Rate Stator current of phase B & $\mathrm{I}_{\mathrm{b}}$ & 53.9 & A \\
Rate Stator current of phase C & $\mathrm{I}_{\mathrm{c}}$ & 53.9 & A \\
Initial phase A of the current & $\mathrm{ph}_{\mathrm{a}}$ & -173.3 & $\mathrm{Degree}$ \\
Initial phase B of the current & $\mathrm{ph}_{\mathrm{b}}$ & 66.7 & $\mathrm{Degree}$ \\
Initial phase C of the current & $\mathrm{ph}_{\mathrm{c}}$ & -53.3 & $\mathrm{Degree}$ \\
Rate excitation source & $\mathrm{E}_{\mathrm{q}}$ & 57 & $\mathrm{~V}$ \\
\hline & & & \\
\hline
\end{tabular}

To evaluate the quality of synchronous motor excitation control system, we compare the system response of the proposed PSO based hybrid PID-FLC Sugeno to a PI controller and PSO based PID controller. For the PI controller, $K_{p}=1$ and $K_{i}=5$ are selected using Ziegler-Nichols combined with trial and error method. For PSO based PID controller, $K_{p}=0.549, K_{i}=5.992$, and $K_{d}=0.5$ are obtained by PSO algorithm. These parameters are also used in combination with the PSO-based hybrid PID-FLC, therein the fuzzy parameters are achieved using PSO as $a=0.3183$, $b=0.75, c_{1}=0.75, c_{2}=0.3943, k_{e}=2.3103, k_{c e}=1156.31$, and $k_{u}=0.012$. In the simulation, disturbance from the sudden increase of the added load, at $\mathrm{t}=2.5 \mathrm{~s}$, causing the phase shift angle to change. The control system will automatically adjust the excitation source to stabilize the power factor $\cos \varphi$. Figure 16 shows the simulation result when load is constant, the $\cos \varphi$ ref change from 0.85 to 0.95 . The figure depicts that all controllers provide minimal errors. By calculating the mean deviation, using the "fit" function in Matlab, the hybrid PID - FLC Sugeno gives the smallest error, 0.51, followed by the PID controller, 2.45, and finally the PI controller 4.03.

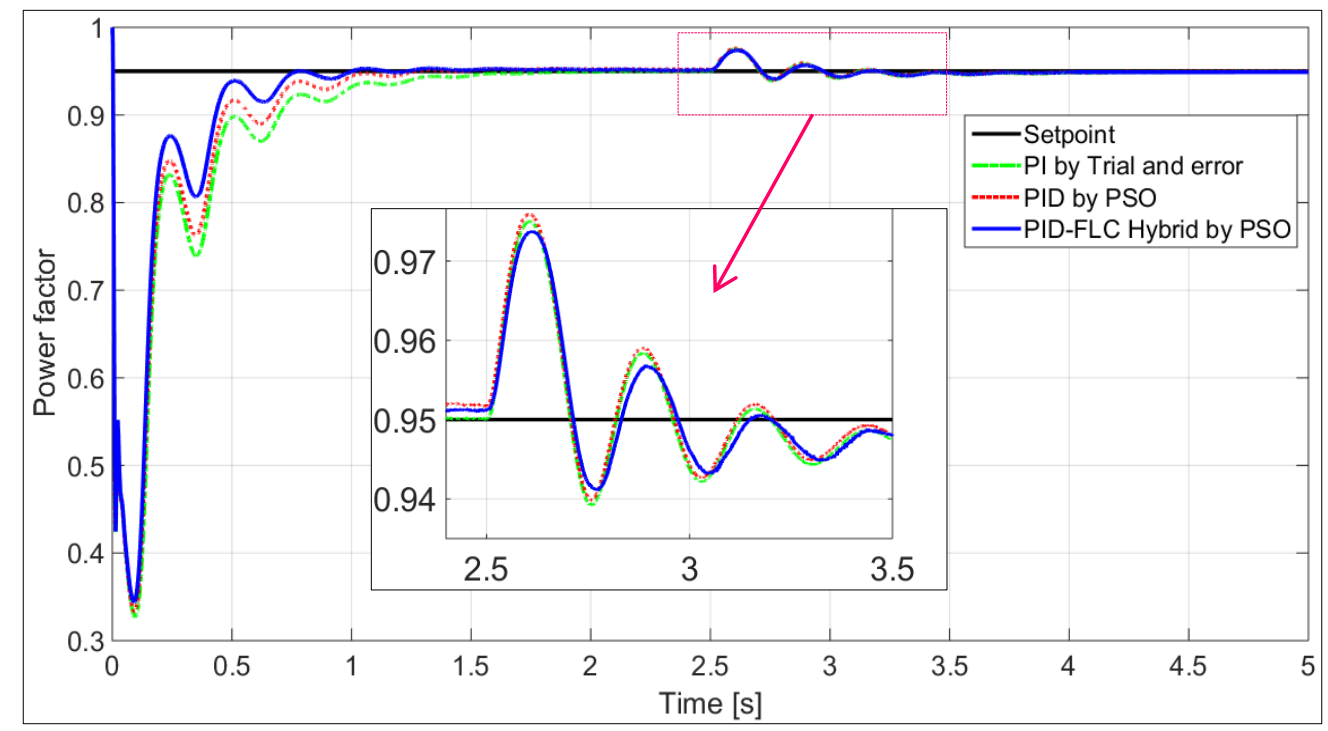

Figure 16. Response of $\cos \varphi$ when $\cos \varphi \_$ref is increased from 0.85 to 0.95

Figure 17 presents the response of the power factor when the load is increased at $t=2.5 \mathrm{~s}$ with desired power factor $\cos \varphi$ _ref $=0.95$. The figure demonstrates that all controllers present a quick response under the load change, where the hybrid PID - FLC presents slightly better performance than the others. 


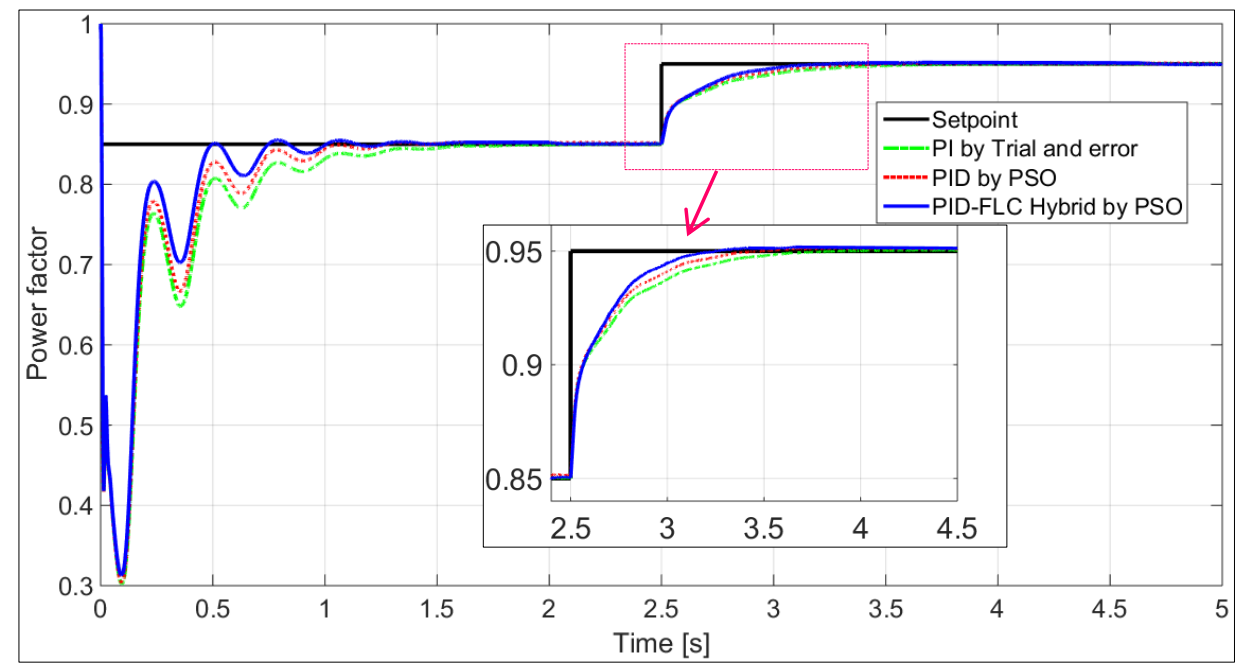

Figure 17. Response of $\cos \varphi$ when $\cos \varphi \_$ref $=0.95$ and load in increased $30 \%$ at $t=2.5 \mathrm{~s}$

The above results show that using the PSO algorithm to optimize controller parameters of the hybrid PID-FLC controller for the excitation control system of a large-capacity synchronous motor in working mode is entirely feasible. Figures 18 and 19 depict the values of IAE after each iteration of the proposed PSO algorithms. These figures illustrate that fitness functions converge to optimal values quickly, after about 11 iterations for PSO-based PID and 36 iterations for the PSO-based hybrid PID-FLC. More importantly, these figures show that the proposed PSO-based hybrid PIDFLC achieved a much smaller IAE than the PSO-based PID controller, 0.51 compared to 2.45, illustrating the advantages of the proposed approach.

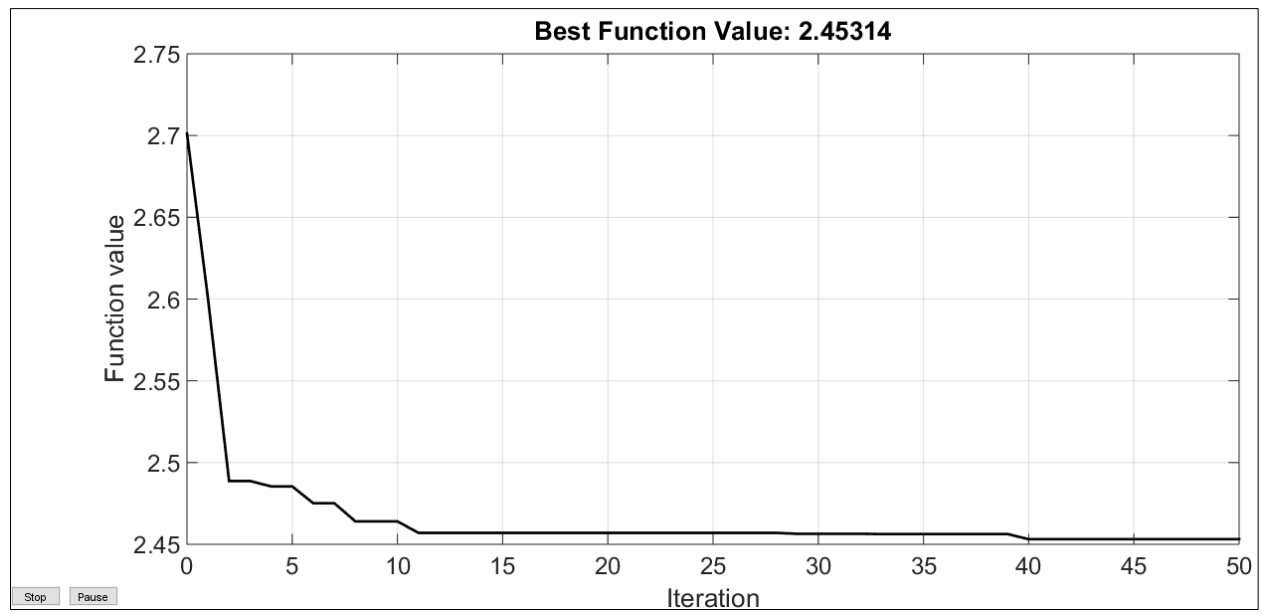

Figure 18. Fitness function of PSO algorithm to tune PID coefficients

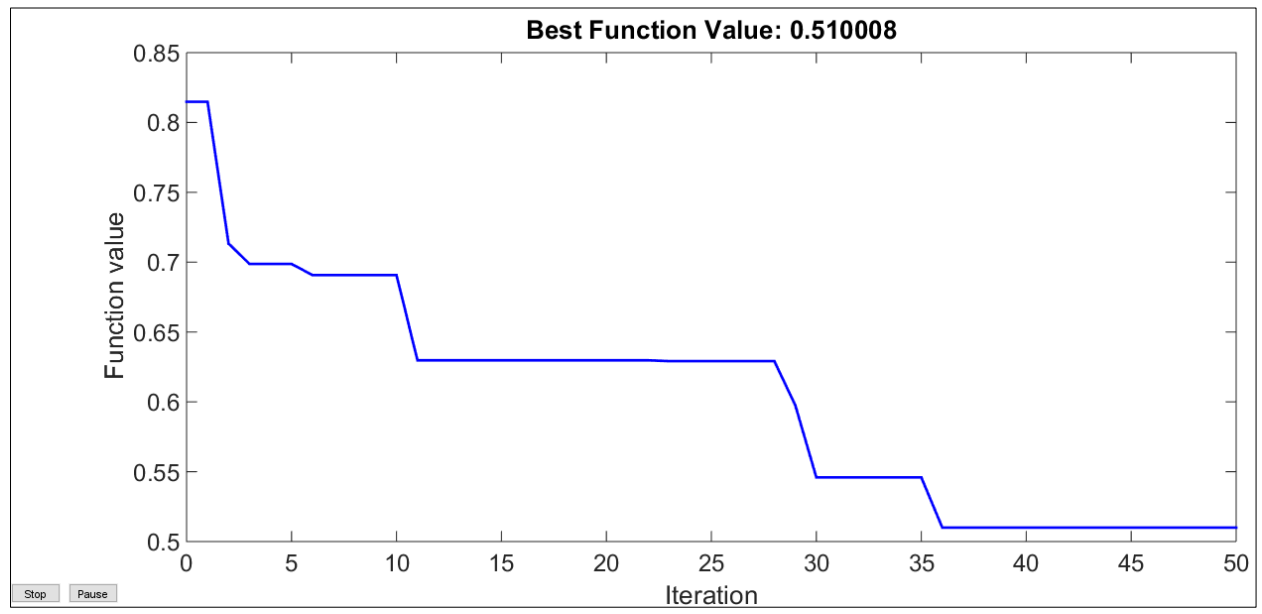

Figure 19. Fitness function of PSO algorithm to tune FLC parameters 


\section{5- Conclusion}

This manuscript introduced a hybrid FLC-Sugeno controller for the excitation system of a large synchronous motor. The effect of load and excitation source on the motor's working mode is critically analyzed to demonstrate the importance of stabilizing the power factor. In the control system, the control parameters were optimized using the PSO algorithm. The PSO is utilized to optimize the tuning coefficients $K_{p}, K_{i}, K_{d}$, and $K_{N}$ of the PID controller. In the FLC Sugeno controller, the membership functions of the input and output variables are optimized. The simulation showed that the proposed controller presents the best control performance among the considered approaches. In our future work, the proposed algorithm will be applied to practical large power transmission systems and other reference tracking control applications.

\section{6- Declarations}

\section{6-1- Author Contributions}

Conceptualization, H.Q.D.; methodology, H.Q.D.; software, H.Q.D., L.V.N. and D.T.N.; validation, H.Q.D., L.V.N. and D.T.N.; formal analysis, Q.H.N.; writing - original draft preparation, H.Q.D. and L.V.N.; writing-review and editing, H.Q.D., L.V.N. and D.T.N. All authors have read and agreed to the published version of the manuscript.

\section{6-2- Data Availability Statement}

Data sharing is not applicable to this article.

\section{6-3- Funding}

This research was funded by Thai Nguyen University of Technology (TNUT), Vietnam.

\section{6-4- Acknowledgements}

The authors gratefully acknowledge Thai Nguyen University of Technology, Vietnam, for supporting this work.

\section{6-5- Conflicts of Interest}

The authors declare that there is no conflict of interests regarding the publication of this manuscript. In addition, the ethical issues, including plagiarism, informed consent, misconduct, data fabrication and/or falsification, double publication and/or submission, and redundancies have been completely observed by the authors.

\section{7- References}

[1] Torrey, D. A. (2020). Chapter 1: Electric Machine Fundamentals. Compendium on Electromagnetic Analysis, 1-119. doi:10.1142/9789813270282_0001.

[2] Say, M. G., \& Say, M. G. (1995). Performance and design of AC machines. CBS Publishers, New Delhi, India.

[3] Barns, B. L. (2009). Electrical Machinery. Transactions of the American Institute of Electrical Engineers, XLV, 830-842. doi:10.1109/t-aiee.1926.5061280.

[4] Horvath, B. (2009). Synchronous Motors \& Sync Excitation Systems. In Western Mining Electrical Association; TM GE Automation Systems, Rapid City, North Dakota, United States. Available online: https://silo.tips/download/synchronousmotors-excitation-control (accessed on January 2022).

[5] Al-Hamrani, M. M., Von Jouanne, A., \& Wallace, A. (2002). Power factor correction in industrial facilities using adaptive excitation control of synchronous machines. IEEE Conference Record of Annual Pulp and Paper Industry Technical Conference, 148-154. doi:10.1109/PAPCON.2002.1015143.

[6] WEG group. (2021). The ABC's of Synchronous Motors: For the Mining Industry. At. Available online: https://www.electricmachinery.com/_files/LR10012.gb.01-11.01_SynchMotors_Mining.pdf (accessed on December 2021).

[7] Araki, M. (2009). PID control; Control systems, robotics, and Automation. In @Encyclopedia of Life Support Systems (EOLSS), Vol. II. Available online: http://www.eolss.net/ebooks/Sample Chapters/C18/E6-43-03-03.pdf (accessed on December 2021).

[8] Ziegler, J. G., \& Nichols, N. B. (1942). Optimum settings for automatic controllers. Transactions of the ASME, 64(11). American Society of Mechanical Engineers (ASME), New York, United States

[9] Allu, N., \& Toding, A. (2020). Tuning with Ziegler Nichols Method for Design PID Controller at Rotate Speed DC Motor. In IOP Conference Series: Materials Science and Engineering, 846(1). doi:10.1088/1757-899X/846/1/012046. 
[10] Bickramdass, R., Persad, P., \& Loutan Jr., K. (2021). Evaluation of an Anthropometric Fast Bowling Machine. HighTech and Innovation Journal, 2(2), 108-119. doi:10.28991/hij-2021-02-02-04.

[11] Jondhale, A. S., Gaikwad, V. J., \& Jondhale, S. R. (2015). Level Control of Tank System using PID Controller-A Review. IJSRD- International Journal for Scientific Research \& Development, 3(10), 3(10), 636-638.

[12] Brenna, M., Foiadelli, F., \& Zaninelli, D. (2010). New stability analysis for tuning PI controller of power converters in railway application. IEEE Transactions on Industrial Electronics, 58(2), 533-543. doi:10.1109/TIE.2010.2047823.

[13] Gani, M. M., Islam, M. S., \& Ullah, M. A. (2019). Optimal PID tuning for controlling the temperature of electric furnace by genetic algorithm. SN Applied Sciences, 1(8). doi:10.1007/s42452-019-0929-y.

[14] Tamalouzt, S., Belkhier, Y., Sahri, Y., Bajaj, M., Ullah, N., Chowdhury, M. S., Titseesang, T., \& Techato, K. (2021). Enhanced direct reactive power control-based multi-level inverter for dfig wind system under variable speeds. Sustainability (Switzerland), 13(16), 9060. doi:10.3390/su13169060.

[15] Pengpraderm, S., Kraikitrat, K., \& Ruangsinchaiwanich, S. (2017). Automatic control of synchronous motor using PI controller for improving power factor. Interdisciplinary Research Review, 12(5), 35-41.

[16] Al-Kababji, M. F., \& Al-Sammak, A. N. B. (2002). Modeling \& simulation of synchronous machine controlled by PID control for the reactive power compensation. The 6th Jordanian International Electrical \& Electronics Engineering Conference JIEEEC, Amman, Jordan, 1-8.

[17] Baygi, S. M. H., Karsaz, A., \& Elahi, A. (2018). A hybrid optimal PID-Fuzzy control design for seismic exited structural system against earthquake: A salp swarm algorithm. In 2018 6th Iranian Joint Congress on Fuzzy and Intelligent Systems, CFIS 2018 (Vols. 2018-January, pp. 220-225). doi:10.1109/CFIS.2018.8336659.

[18] Wu, C., Liu, J., Jing, X., Li, H., \& Wu, L. (2017). Adaptive fuzzy control for nonlinear networked control systems. IEEE Transactions on Systems, Man, and Cybernetics: Systems, 47(8), 2420-2430. doi:10.1109/TSMC.2017.2678760.

[19] Paul, S., Arunachalam, A., Khodadad, D., \& Rubanenko, O. (2020). Fuzzy Tuned PID Controller for Vibration Control of Agricultural Manipulator. In HORA 2020 - 2nd International Congress on Human-Computer Interaction, Optimization and Robotic Applications, Proceedings (pp. 1-5). IEEE. doi:10.1109/HORA49412.2020.9152848.

[20] Boudia, A., Messalti, S., Harrag, A., \& Boukhnifer, M. (2021). New hybrid photovoltaic system connected to superconducting magnetic energy storage controlled by PID-fuzzy controller. Energy Conversion and Management, 244, 114435. doi:10.1016/j.enconman.2021.114435.

[21] K1liç, A., \& Altaş, I. (1996). Power Factor Correction of Synchronous Motor Using Fuzzy Logic. Mathematical and Computational Applications, 1(1), 66-72. doi:10.3390/mca1010066.

[22] Keçecioğlu, Ö. F., Açikgöz, H., Yildiz, C., Şekkeli, M., \& Gani, A. (2016). Simulation Study on Power Factor Correction Controlling Excitation Current of Synchronous Motor with Fuzzy Logic Controller. International Journal of Intelligent Systems and Applications in Engineering, 4(Special Issue-1), 229-233. doi:10.18201/ijisae.2016specialissue-146979.

[23] Kennedy, J., \& Eberhart, R. (1995). Particle swarm optimization. Proceedings of ICNN'95 - International Conference on Neural Networks, IEEE. Perth, WA, Australia. doi:10.1109/icnn.1995.488968

[24] Zeng, W., Zhu, W., Hui, T., Chen, L., Xie, J., \& Yu, T. (2020). An IMC-PID controller with Particle Swarm Optimization algorithm for MSBR core power control. Nuclear Engineering and Design, 360, 110513. doi:10.1016/j.nucengdes.2020.110513.

[25] Kaukonen, J. (1999). Salient pole synchronous machine modelling in an industrial direct torque controlled driver application. $\mathrm{PhD}$ Thesis, Lappeenranta University of Technology, Lappeenranta, Finland.

[26] Khanh, B. Q., Vinh, D. Q., Dang, P. Q., \& Dich, N. Q. (2020). Industrial electric drive control. Scientific and technical Publishers, 1-24.

[27] Kuo, I. H., Horng, S. J., Kao, T. W., Lin, T. L., Lee, C. L., \& Pan, Y. (2009). An improved method for forecasting enrollments based on fuzzy time series and particle swarm optimization. Expert Systems with Applications, 36(3 PART 2), $6108-6117$. doi:10.1016/j.eswa.2008.07.043.

[28] Farh, H. M. H., Eltamaly, A. M., \& Othman, M. F. (2018). Hybrid PSO-FLC for dynamic global peak extraction of the partially shaded photovoltaic system. PLoS ONE, 13(11). doi:10.1371/journal.pone.0206171.

[29] Rahma, A., \& Khemliche, M. (2014). Combined approach between FLC and PSO to find the best MFs to improve the performance of PV system. 2014 International Conference on Electrical Sciences and Technologies in Maghreb, CISTEM 2014. doi:10.1109/CISTEM.2014.7077038. 
[30] Anitha, T., Gopu, G., Nagarajapandian, M., \& Devan, P. A. M. (2019). Hybrid Fuzzy PID Controller for Pressure Process Control Application. 2019 IEEE Student Conference on Research and Development, SCOReD 2019, $129-133$. doi:10.1109/SCORED.2019.8896276.

[31] Brehm, T., \& Rattan, K. S. (1994). Hybrid fuzzy logic PID controller. IEEE International Conference on Fuzzy Systems, 3 , 1682-1687. doi:10.1109/naecon.1993.290839.

[32] Gomaa Haroun, A. H., \& Li, Y. Ya. (2017). A novel optimized hybrid fuzzy logic intelligent PID controller for an interconnected multi-area power system with physical constraints and boiler dynamics. ISA Transactions, 71, 364-379. doi:10.1016/j.isatra.2017.09.003.

[33] Erenoglu, I., Eksin, I., Yesil, E., \& Guzelkaya, M. (2006). An intelligent hybrid fuzzy PID controller. 20th European Conference on Modelling and Simulation: Modelling Methodologies and Simulation Key Technologies in Academia and Industry, ECMS 2006, 62-66. doi:10.7148/2006-0062.

[34] Torreglosa, J. P., Jurado, F., Garca, P., \& Fernndez, L. M. (2011). Application of cascade and fuzzy logic based control in a model of a fuel-cell hybrid tramway. Engineering Applications of Artificial Intelligence, 24(1), 1-11. doi:10.1016/j.engappai.2010.08.009. 